plants have been derived from sets or seeds, and in the former case the growth and bulbing of the plant are affected by the storage treatments to which the sets have been subjected. Heath and his co-workers ${ }^{2-5}$, concerned especially with the effects of storage treatments of onion sets on the 'bolting' of the resulting plants, and confirming and extending the results of earlier workers ${ }^{1,7}$, found that hightemperature storage given throughout the winter, or for the last eight weeks, delays ripening, and gives larger yields, whereas high-temperature storage for the first eight weeks has no such effect. These treatments also reduced the incidence of 'bolting', as did storage at $0^{\circ}$ either for the whole or the first eight weeks of the winter. The effects of storage treatments on bolting and bulbing were difficult to disentangle; but Heath and Holdsworth 4 concluded that the hightemperature treatments suppress bolting and affect bulbing separately.

So far as the treatments given here parallel those used by Heath in the treatment of onion sets, the results are similar; but with a non-flowering strain of shallot, there is no possibility of any confusion between the effects of the several storage treatments on flowering and bulbing. With the shallot, therefore, we can be sure that we are dealing with a primary effect on bulb initiation and swelling, and not with some secondary effect on these phenomena that operates through the suppression of flowering. If, in the shallot, as in the onion, bulbing is controlled photo. periodically, the effects of these storage treatments would be at least partially explained if their primary effect was in some way to increase the critical photoperiod necessary for bulb initiation. The shallots are grown during a period of lengthening days (AprilJune), and the effect of an increase in this critical photoperiod would be to delay the onset of bulbing. Further ${ }^{1}$, with onions, the greater the excess of the photoperiod experienced over the critical photoperiod required for bulb initiation, the more rapid are the ripening processes. Hence, if the critical photoperiod is increased, but is still less than the photoperiods experienced after bulbing has begun, the difference between the critical and the experienced photoperiods will be reduced, and the processes of bulb ripening retarded, that is, the period of bulbswelling extended. Delayed bulb initiation, a prolonged period of bulb swelling and delayed ripening are the precise effects on the resulting plants of storage throughout the winter, or for the first part of the winter at $30^{\circ} \mathrm{C}$., or for the first part of the winter at $0-4^{\circ} \mathrm{C}$. (or for the whole storage period at $0-4^{\circ} \mathrm{C}$. with small bulbs) of shallot bulbs before planting. The data available do no more, however, than permit the suggestion that the storage treatments operate on the lines indicated, affecting in some way the critical photoperiod required for the initiation of bulbing in the resulting plants.

Botanical Department, University,

Manchester 13. March 2.

${ }^{1}$ Magruder, R., and Allard, H. A., J. Agric. Sci., 54, 719 (1937).

'Heath, O. V. S., Ann. App. Biol., 30 (3), 208 (1943).

3 Heath, O. v. S., Ann. App. Biol., 30 (4), 308 (1943).

- Heath, O. v. S., and Holdsworth, M., Nature, 152, 334 (1943).

s Heath, O. V. S., and Mathus, B. B., Ann. App. Biol., 31 (3), 173 (1944).

- Scully, N. J., Parker, M. W., and Borthwick, H. A., Bot. Gaz., 107, 52 (1943).

'Thompson, H. C., and Smith, O., Bull. Cornell Agric. Exp. Stat., No. 708 (1938).

\section{Streptococcus fæcalis in E. histolytica Infections}

Bacteriological studies conducted upon a series of cases of relapsing amcobiasis showed that changes occurred in the relative distribution of organisms in the fæces during the active stages of the disease ${ }^{2}$. One particular change was the abnormal prevalence of enterococci in dysenteric exudates. In most cases, these enterococci were identified as Streptococcus foecalis.

When a 1 per cent glucose-broth culture or culturefiltrate of certain strains of Streptococcus foccalis was added to a phosphate-buffered suspension of $E$. histolytica in equal volume, the amœbæ were observed to disintegrate in one or two hours. This effect was a specific result of the growth of Streptococcus foccalis in peptone media containing glucose, and was due apparently to some substance or substances formed during the fermentation of glucose. When glucose was fermented by growing cultures of coliform organisms or staphylococci, no such action was observed.

The complete identity of the metabolites which are toxic to $E$. histolytica has not as yet been ascertained, but the properties are consistent with a heat-stable, water-soluble substance not readily adsorbed on surfaces. Lactic acid ${ }^{2}$ shows a similar type of activity against $E$. histolytica in vitro in concentrations of $0.05 M$; this concentration is readily attained in glucose-broth cultures of Streptococcus foecalis, and removal of lactic acid from such cultures by etherextraction almost eliminates their activity. The effect is not a direct consequence of changes in the hydrogen ion concentration of the media, though the action of lactic acid increases as the $p H$ falls, and lactates, which are inactive at $p H .7$, show activity at $p \mathrm{H}$. It is probable, therefore, that the principal toxic metabolite is lactic acid.

An effect was also observed in vivo when young rats, experimentally infected with $E$. histolytica by the method of Jones ${ }^{3}$, were fed with living cultures of the appropriate strains of Streptococcus foecalis. The degree of amœbic infection was consistently lowered, and when cultures of the two organisms were mixed before inoculation of the rats $E$. histoly. tica lost its infectivity within one hour.

Enterococci of the Streptococcus foecalis group are normal members of the intestinal flora of man and certain animals, especially in the small intestine. Their prevalence in the colon becomes increased dur. ing the 'hurry' of the small intestine caused by diarrhœa. As a result of this, $E$. histolytica becomes more closely associated with Streptococcus foecalis in the colon during the active stages of amœbiasis. It is possible, therefore, that the process described above plays a part in the natural history of an amœbic infection.

\section{G. T. STHWART}

Liverpool School of Tropical Medicine.

W. R. JONES

M. A. T. Rogens

Imperial Chemical Industries, Ltd.,

Biological Laboratories, Hexagon House,

Manchester 9. March 3.

1 Stewart, G. T., Trans. Roy. Soc. Trop. Med. Hyg., 41, 75 (1947).

'Birch-Hirschfeld, L., Z. Hyg. u. Infect., 119, 91 (1937)

'Jones, W. R., Ann. Trop. Med. Parasit., 40, 130 (1946). 